\title{
Keep calm e mude o código: um estudo de code switching no Facebook
}

\section{Keep Calm and Change the Code: A Codeswitching Study on Facebook}

\author{
Wélica Cristina Duarte de Oliveira* \\ *Universidade do Estado de Mato Grosso (UNEMAT), Tangará da Serra, Mato Grosso \\ / Brasil \\ welicacd@gmail.com \\ https://orcid.org/0000-0003-3621-5073 \\ Barbara Cristina Gallardo** \\ **Universidade do Estado de Mato Grosso (UNEMAT), Tangará da Serra, Mato Grosso \\ / Brasil \\ barbarag@unemat.br \\ https://orcid.org/0000-0001-8055-0990
}

RESUMO: Este artigo tem como objetivo analisar a incidência do fenômeno code-switching na interação entre falantes bi/multilíngues, na rede social Facebook. Ao considerar o dinamismo e o caráter multimodal da comunicação, compreendemos que é fundamental que a formação de professores de línguas volte-se às discussões sobre os muitos cenários linguísticos advindos da diversidade social e humana. Entre esses cenários está o ciberespaço, onde tecnologia, língua e cultura estão numa relação dialógica diferente da que acontece no espaço físico. No Facebook, por exemplo, percebemos essa relação nas práticas de code-switching, uma possibilidade na comunicação entre falantes bi/multilíngues que têm a capacidade de mudar o código dependendo do interlocutor, do que querem dizer e do que estão sentindo. A possibilidade de rastreamento da Comunicação Mediada por Computador nos permitiu observar como os sujeitos bi/multilíngues se apropriam do ambiente virtual para interagir com amigos de línguas e culturas diferentes e vivenciar essas línguas e culturas, na exposição de suas identidades por meio do code-switching. Os dados coletados durante quatro meses compreendem postagens e interações assíncronas entre esses falantes com/destinadas a amigos bi/multilíngues e também monolíngues. Os resultados apontam as vantagens da flexibilidade linguística de falantes bi/ multilíngues, no trânsito entre culturas em um contexto virtual de interação e a atenção que esses sujeitos despendem a esse contexto e à diversidade de interlocutores. O domínio de mais de uma língua e a familiaridade com a rede social virtual onde aconteceram as interações deram maior liberdade e autonomia para que alternassem línguas e, assim, se expressassem de acordo com suas necessidades, sem obedecer estritamente a regras predeterminadas 
de uma ou outra língua, ou seja, sentiram-se livres para expor por meio da linguagem as culturas que os habitam, tendo em vista as características do meio virtual que desvincula a presença social da presença física.

PALAVRAS-CHAVE: ciberespaço; multilinguismo; code-switcbing.

ABSTRACT: This article aims to analyze the incidence of the code-switching phenomenon in the interaction between bi-multilingual speakers in the social network Facebook. When considering the dynamism and multimodal character of communication, we understand that it is essential that the education of language teachers include discussions on the many linguistic scenarios arising from social and human diversity. Among these scenarios is the Cyberspace, where technology, language and culture are in a dialogical relationship different from the one that happens in the physical space. In Facebook, for example, we observed this relationship in code-switching practices, possible between bi / multi-lingual speakers that are able to change the code depending on the interlocutor, on what they want to say and on what they are feeling. The possibility of tracking Computer-Mediated Communication allowed us to observe how $\mathrm{bi} /$ multilingual speakers appropriate the virtual environment to interact with friends from different languages and cultures and to experience those languages and cultures in exposing their identities through codeswitching. The data collected during four months comprised asynchronous posts and interactions between these speakers with both bi/multilingual and monolingual friends. The results point to the advantages of linguistic flexibility of bi/multilingual speakers, in the traffic among cultures in a virtual context of interaction and the attention they have in this context and the diversity of interlocutors. The mastery of more than one language and the knowledge of the social network where the interactions took place gave greater freedom and autonomy for speakers to alternate languages and thus express themselves according to their needs without strictly following predetermined rules of one or the other language, that is, speakers felt free to expose themselves through language, expose the cultures that inhabit them, following the characteristics of the virtual environment that unties the social presence of the physical one.

KEYWORDS: cyberspace; multilinguism; code-switching.

\section{Introdução}

Os propiciamentos que a tecnologia oferece aos usuários da internet aumentam à medida que surgem novos aplicativos e plataformas digitais com características da Web 2.0. As práticas de code-switching, ${ }^{1}$ por exemplo,

\footnotetext{
${ }^{1}$ A tradução para o português de code-switching é alternância linguística ou troca de códigos. Optamos por usar o termo em inglês ao longo do trabalho para pontuar que, para nós, a nomenclatura em inglês exprime com mais especificidade a ideia deste fenômeno do que sua tradução. Sugerimos que a opção por manter um termo em inglês em um texto em português agrega discussões condizentes com a natureza desta pesquisa.
} 
que acontecem na comunicação mediada por computador (CMC), chamam a atenção para os modos de participação de usuários bilíngues em práticas discursivas transnacionais. São práticas ricas porque indicam a construção de identidades em meios virtuais e socioculturamente situados, expressas no trânsito de diferentes discursos (GARCIA, 2009) que são definidos pelos falantes, em um espaço público e sem fronteiras geográficas e que, de modo similar, podem ser delimitados pelos usuários da internet. ${ }^{2}$

Escolhemos o contexto virtual para realizar este estudo porque os avanços tecnológicos e a expansão dos fenômenos da globalização possibilitaram a formação de novas subjetividades que se manifestam principalmente por meio da construção linguística e semiótica. Exigem, assim, uma linguagem que dê conta de suprir a presença social nos contextos de interação (SUNDÉN, 2003). O estudioso Pierre Lévy (2007, p. 11) vê o crescimento do ciberespaço como uma abertura de um novo espaço de comunicação. A participação neste espaço registra a heterogeneidade da linguagem de forma significativa e incentiva a reflexão sobre a diversidade de discursos, a partir do contato com sistemas de referências em um ambiente distinto de organização. Acreditamos que, como formadores de professores de línguas estrangeiras, cabe-nos explorar as potencialidades mais positivas desse espaço nos planos político, sociocultural e humano. Dentro de nossa área de atuação profissional, esses planos podem ser abordados por meio do estudo da inter-relação entre língua, tecnologia e cultura no contexto das novas tecnologias de informação e comunicação (NTIC).

Por se tratar de um espaço não neutro, mas mediado, cujas características específicas afetam de modos específicos tais construções identitárias, neste artigo temos como objetivo analisar práticas de codeswiching (doravante chamados de CS) de usuários bi/multilíngues na

\footnotetext{
${ }^{2}$ Partimos do princípio de que quanto mais as pessoas se familiarizam com os discursos, códigos e práticas de uma cultura (GARCÍA, 2009), mais elas se apropriam da língua(gem) dessa cultura, da subjetividade presente nos enunciados. No meio virtual, quanto mais conhecimento dos letramentos digitais, mais benefícios agregados têm os usuários, no sentido de participações bem-sucedidas, por exemplo, escolha do público que visualizará determinadas postagens, em uma escala sem fronteiras nacionais. No Facebook, por exemplo, é possivel criar smart lists (listas inteligentes) e classificar os amigos em melhores amigos, conhecidos, família etc. e criar listas próprias, como por exemplo, amigos de infância. Assim, as informações que interessam a um grupo específico de amigos (por exemplo, fotos do aniversário de 80 anos da avô) não aparecem na página dos amigos que não têm nenhuma relação com este post (GALLARDO, 2013).
} 
rede social Facebook, a fim de verificar os momentos em que fazem determinadas escolhas linguísticas na língua materna ou em uma língua estrangeira e a relação dessas escolhas com as identidades pretendidas, com os interlocutores diretos e indiretos e com o contexto virtual de interação. Trata-se de um recorte de um estudo mais amplo que realizamos em nosso grupo de pesquisa, em que registramos ocorrências dessa natureza em posts e interações entre dois interlocutores, e que levou em consideração: a) as circunstâncias em que elas ocorreram; b) os interlocutores envolvidos; c) a língua que prevaleceu; e d) os objetivos e/ou motivação para a troca, tendo em vista o contexto virtual em que as interações aconteceram. A comunicação, nestes casos, aconteceu entre: a) falantes de duas ou mais línguas; e b) entre bilíngues compatriotas comunicando-se com falantes nativos de sua segunda língua/língua estrangeira (doravante chamada de LE).

Abordamos, a seguir, os principais fatores que se atrelam à prática de CS, a fim de relacioná-los às experiências de sujeitos bilíngues na interação virtual.

Escolhemos analisar o fenômeno CS pela dinamicidade que ele imprime nos enunciados de falantes que operam em duas ou mais línguas. Assim, conforme já argumentamos, ele tem o potencial de revelar questões identitárias importantes referentes aos participantes imersos em práticas de culturas heterogêneas espalhadas no mundo todo, conectadas virtualmente em um espaço transnacional. Tendo em vista a concepção de identidade que se elabora na relação com o outro (BARTH, 1969 apudCUCHE, 2002), compreendemos que é a cada interação que as identidades são construídas, por meio das linguagens disponíveis para a escolha do falante, escolhas que não são somente linguísticas, mas refletem aspectos cognitivos e socioculturais. No meio virtual, o discurso (que engloba esses aspectos) pode ser moldado por características tecnológicas da CMC, por exemplo, por meio da escrita com características da fala, dos emojis, das normas de participação de uso da língua, de comportamento, do objetivo da interação, do grau de afinidade/proximidade entre o/os interlocutor/es, ${ }^{3}$ dentre outras.

\footnotetext{
${ }^{3}$ Um exemplo de um aspecto cognitivo pode ser observado no estudo de Gee (2005) que discorre sobre os padrões estabelecidos na mente por meio de experiências, por exemplo, a do significado da palavra amigo. O significado do meio físico é incorporado ao meio virtual no Facebook ("agora vocês são amigos"). O trânsito entre meios de sociabilidade diversos (on e offline) por vezes se chocam e se misturam, deixando o usuário exposto e aberto ao estabelecimento/manutenção de laços produtivos e improdutivos.
} 
Sendo livre de fronteiras geográficas, o ciberespaço possibilita o alcance de pessoas distantes de uma forma inédita e de baixo custo. ${ }^{4}$ Isso facilita o encontro virtual entre falantes de línguas diferentes e de usuários, da língua e da rede, localizados geograficamente em lugares distintos. Promove também a manifestação de novos meios de expressão, por meio da linguagem. Neste estudo, por exemplo, identificamos alguns aspectos da interação em línguas que poderiam ou não ser da língua materna (doravante chamada de LM) do falante e do interlocutor, o que nos permitiu levantar informações e discussões a respeito dos recursos utilizados referentes ao CS, as quais apresentamos a seguir.

\section{Considerações sobre o CS}

Antes dos anos 1970, o CS era visto como um fenômeno de interferência, como parte do desempenho bilíngue imperfeito, por mais que fosse conhecida a fluência dos falantes em ambas as línguas (MOZZILLO, 2009). Hoje entendemos o fenômeno, ancorados nos estudos de Auer (1999), Grosjean (1982), entre outros, como um recurso comunicativo, no qual os falantes de mais de uma língua julgam as vantagens e calculam as consequências de suas opções linguísticas. Vemos então que a motivação para este fenômeno relaciona-se diretamente com a possibilidade de maiores recompensas comunicativas. As pesquisas sobre a manifestação de CS na internet são facilitadas pelo registro impresso das ocorrências que dispensam a transcrição de dados.

O CS vem sendo abordado pelos estudiosos do campo do bilinguismo e das línguas em contato, tornando-se um assunto de interesse entre os pesquisadores da linguagem (PORTO, 2007; SHIN, 2017). Conforme pontuamos, igualmente aos falantes monolíngues, ${ }^{5}$ os bilíngues têm a opção de alternar a variante particular sempre que iniciam uma conversa. $O$ que os diferencia é que, no caso dos bilíngues, há a opção de "alternar entre códigos

\footnotetext{
${ }^{4}$ Para ter acesso doméstico, os usuários têm que pagar uma taxa mensal a uma empresa. Atualmente, com a popularização dos serviços de wi-fi (redes sem fio), muitos estabelecimentos (cafés, shoppings, restaurantes) oferecem acesso à internet gratuitamente aos seus clientes, como forma de atrai-los e também de fazer propaganda por meio da utilização deste serviço aos clientes, já que o check-in para essas conexões é feito via Facebook.
}

${ }^{5}$ Falantes de uma só língua. 
ou mesmo misturá-los na interação, criando, deste modo, enunciados híbridos, caracterizados como CS” (GUMPERZ, 1982, p. 59). Gumperz descreve o CS como sendo "a justaposição dentro do mesmo fragmento de fala de passagens pertencentes a dois sistemas ou subsistemas gramaticais distintos" ${ }^{\prime \prime}$ (tradução nossa). ${ }^{7}$

Pesquisas científicas, tais como as de Jacobson (1998), Bathia e Ritchie (1996), Montes-Alcalá (2001) sugerem que o fenômeno CS não é randômico, e muitos menos, resultado da falta de proficiência na LE envolvida, já que o enunciado híbrido proveniente deste fenômeno carrega funções e motivações sociopragmáticas e está sujeito a algumas restrições gramaticais. Conforme esses estudos, o CS é "um mecanismo estruturado de seleção de duas ou mais línguas na construção de sentenças" (JACOBSON, 1998 p. 1). Pesquisadores da área da sociolinguística analisam as funções dessa prática no discurso, entendendo a importância desse recurso enquanto "mapeador" das relações sociais definidas e, conforme nossa compreensão, uma estratégia desejável e benéfica do ponto de vista pragmático, em conformidade com a situação social, o interlocutor e o meio.

Assim, sugerimos que este fenômeno caracteriza-se como um dispositivo empregado de forma criativa a favor da liberdade e que está diretamente relacionado às preferências e/ou competências divergentes dos falantes.

A partir das ocorrências de CS, Dabène e Moore (1995 apud MOZZILLO, 2009) sugeriram uma classificação para este fenômeno, a qual Mozzillo compreende como uma das mais abrangentes: o CS intrasentencial, o intersentencial e o entre enunciados. Segundo essa classificação, o intra-sentencial pode ocorrer sob as formas: unitária (apenas um elemento da frase) ou segmental (segmentos de cada língua se alternam). Nessa primeira classe, há ocorrências com adaptação ou sem adaptação à língua de base. O intersentencial ocorre no momento em que as línguas se alternam de uma sentença a outra, ou seja, ocorre noutro turno

\footnotetext{
${ }^{6}$ No original: "The juxtaposition within the same speech exchange of passages of speech belonging to two different grammatical systems or subsystems" (GUMPERZ, 1982, p. 59).

${ }^{7}$ Todas as traduções deste artigo foram feitas pelas autoras.

${ }^{8}$ No original: "[...] a structured mechanism of selection of two or more languages in the construction of sentences".
} 
da conversação. Já o entre enunciados implica em alternar depois de um longo período da conversação na outra língua, porém no mesmo diálogo.

Cada um desses tipos de CS carrega suas motivações, variando entre marcação de persuasão, provocação, efeito cômico, mudança de assunto, aproximação da identidade com o grupo, entre outras. $\mathrm{O}$ ambiente ou a presença do "outro", do "diferente", também influenciam no que se refere à motivação, confirmando, assim, as ponderações de Fisher (1972 apud MOZZILLO, 2009) e Myers-Scotton (1992). Na análise de interações virtuais que apresentamos neste artigo, verificamos as situações nas quais os participantes fazem o CS nas modalidades intra-sentencial e intersentencial, e ponderamos sobre essas escolhas.

\section{Tecnologia, identidade e CS}

A ampliação dos encontros nos espaços sociais digitais inovou os modos de comunicação e o gerenciamento de identidades nas interações em uma rede social online. Tornou-se, então, um desafio aos interlocutores que precisam recorrer a recursos linguístico-semióticos propiciados pelo meio digital, para a construção de uma identidade digital. Podemos dizer que o uso do CS nas interações digitais torna essa dinâmica mais complexa pois, de acordo com Myers-Scotton (1993), ao escolher um ou outro código, o sujeito estabelece uma negociação contínua para suprir a necessidade de acomodação ao encontro intercultural. Esta autora explica que as competências comunicativas dos interlocutores permitem a escolha de uma variante linguística em detrimento de outra para a expressão do significado.

Identificamos, nos participantes dessas interações, características do sujeito pós-moderno, conforme descrito por Hall (2006), um sujeito que, diferentemente do sujeito do iluminismo e o sociológico, ${ }^{9}$ é visto como não tendo uma identidade unificada e estável, mas composto por várias identidades instáveis, sendo, assim, fragmentado, fruto do estabelecimento

\footnotetext{
${ }^{9}$ Para discutir a identidade cultural na pós-modernidade, Hall (2006) faz uma revisão da noção da identidade em diferentes períodos históricos. O sujeito do Iluminismo, segundo este autor, é marcado pela unificação, pela razão e pela consciência. O sujeito sociológico é constituído pela interação entre o eu e o outro, que forma o que Hall chama de o "eu real", "modificado em um diálogo contínuo com os mundos culturais "exteriores" e as identidades que esses mundos oferecem" (2006, p. 11). O sujeito da pós-modernidade é o que identificamos neste estudo.
} 
de uma fronteira ampliada entre o tecnológico e o cultural (BUZATO, 2009), dentre outros movimentos oriundos da globalização contemporânea. O trânsito desses sujeitos com "outro modo de ver o mundo e o outro, [com] vozes que se entrecruzam e se entrelaçam no inconsciente" (CORACINI, 2007 , p. 152) provoca reconfigurações identitárias e rearranjos subjetivos que, em uma perspectiva pós-moderna, pode garantir a agência nos diversos contextos mono/plurilíngues, on e offline, que circulam, tendo em vista os objetivos da interação, os interlocutores envolvidos etc. (CORACINI, 2007). Ainda em uma perspectiva pós-moderna, Garcia (2009) considera as práticas de translaguaging, das quais o CS faz parte, uma commodity de valor linguístico essencial no século XXI.

A relação, portanto, entre tecnologia, identidade, comunicação e CS, no movimento da cibercultura potencializa práticas discursivas mediadas pelas tecnologias digitais, dentre elas, a de sujeitos multilíngues. Como argumento, compartilhamos as ponderações de Lévy $(2007$, p. 11) que afirma que o ciberespaço oferece "formas de comunicação diferentes" aos "jovens ávidos" para que possam experimentar novas formas de manifestação em um novo contexto. Para isso, a hodierna relação entre tecnologia e linguagem abarca uma variedade de discussões, questionamentos e teorizações estudados sob os termos "letramento digital", "discurso eletrônico", "CMC", "hipertexto", entre outros (VILAÇA; ARAÚJO, 2012). A variedade de características de cada uma dessas áreas incentiva o desenvolvimento de pesquisas relacionadas às relações sociais, à política, à expressão do ser humano, à linguagem, à educação e, portanto, pertinentes às discussões e reflexões teóricas de educadores da área da linguagem interessados em registrar as competências linguísticas no contexto digital.

A Web 2.0 representa uma zona de contato para a construção identitária, se levada em consideração a experiência mútua de diferentes culturas nacionais que circulam nos espaços de sociabilidade on/offline do mundo globalizado e que se relacionam de forma assimétrica. Esses novos espaços de participação incentivam a experimentação de identidades através do contato entre discursos e culturas heterogêneas (GALLARDO, 2016). Da mesma forma, sugerimos que o CS também pode ser compreendido como uma zona de contato ${ }^{10}$ entre as diferentes línguas e culturas que constituem

\footnotetext{
${ }^{10}$ No sentido dado por Pratt (1999) ao discorrer sobre a transculturação, e de Kramsch e Uryu (2011) no contato intercultural na internet, lugar que chamam de terceiro espaço.
} 
o sujeito e que se manifestam por meio da linguagem. Nas redes sociais virtuais, essas manifestações ficam registradas e disponíveis online.

\section{Linguagem e internet}

Paralelamente às questões educacionais voltadas ao letramento digital, uma grande parte da população, nos últimos anos, passou a explorar informalmente as possibilidades oferecidas pela internet para a interação à distância. Isto aconteceu devido à popularização da internet e ao avanço das possiblidades de exploração das práticas digitais. Consequentemente, a comunicação digital passou a ser vista como uma modalidade de comunicação que vem afetando a linguagem e crescendo fortemente (BRAGA, 2007; MARCUSCHI, 2008). Nesse contexto, novos gêneros digitais surgiram, tais como chats, fóruns, e-mails, entre outros (MARCHUSCHI, 2002 apud BRAGA, 2007, p. 185; MARCUSCHI, 2008). De acordo com a literatura a respeito do tema, cremos que devido ao imediatismo próprio dessa modalidade de comunicação, a preocupação de muitos foi despertada, principalmente da imprensa, que temia o advento do "internetês" e sua transposição para os gêneros do contexto offline. No entanto, como lembra Braga (2007), essas críticas expandiram o interesse pela linguagem digital, gerando novas discussões a respeito da organização hipertextual na escrita e na leitura, bem como a exploração de múltiplas modalidades expressivas (KRESS; VAN LEEUWEN, 2006), o acesso e a exclusão social (JUNQUEIRA; BUZATO, 2013), o potencial de democratização do meio digital (LÉVY 2007, 2011) e a potencialidade de opressão das novas tecnologias (POSTER, 2003).

A linguagem nesse meio digital passou a, naturalmente, explorar recursos expressivos oferecidos pelo meio e, assim,

a escrita, a título de exemplo, precisou encontrar formas alternativas (estruturais, gráficas e visuais) para transmitir informações que, na comunicação oral face a face, valiam-se das convenções prosódicas ou da linguagem corporal (BRAGA, 2007, p. 187).

Neste estudo, inferimos que, para falantes bilíngues, essas práticas se organizam de modo linguisticamente diferente das de indivíduos monolíngues. A estrutura das línguas que são familiares aos usuários é capturada e, junto com ela, aspectos culturais que modelam as relações 
sociais. Este fato traz consequências políticas, uma vez que esta escolha é influenciada pelo prestígio das línguas dominantes (GARCÍA, 2009). Por exemplo, a língua falada é mais dominante do que a língua de sinais, a escrita predomina em relação à falada e a LI e o Mandarim são mais prestigiados do que as línguas indígenas (CRYSTAL, 2003). Como a língua falada está presente na CMC e falantes bi/multilíngues de línguas majoritárias e minoritárias (no sentido quantitativo) são usuários de redes sociais virtuais, este é um fato que nos interessa, pois a análise de suas interações online pode indicar como esses sujeitos constroem linguisticamente suas identidades (só na LM, só na língua portuguesa ou nas duas línguas), tendo em vista os contextos virtuais como o Facebook que os "transportam" para além do local de suas aldeias, tomando o usuário "como centro de uma rede egocêntrica” (BOYD; ELLISON, 2007 apud GALLARDO, 2013, p. 25).

Compartilhamos com Crystal (2001) a noção de que essas formas de comunicação provocam uma grande evolução nos conceitos de língua, em suas modalidades falada e escrita. De acordo com Herring (1996), a CMC acontece nos gêneros e-mails, discussões online, mensagens instantâneas, fóruns de discussões, mensagens de texto, blogs, chats, entre outros (CRYSTAL, 2006 apud SHAFIE; NAYAN, 2013, p. 187). O contexto do Facebook abrange a maioria desses gêneros.

A partir dos dados levantados, ${ }^{11}$ tivemos a informação de que a maioria dos entrevistados utilizava o Facebook para socializar, manter contato, comentar e curtir fotos dos seus amigos, assim como constatado no estudo de Boyd e Ellison (2007), Lankshear e Knobel (2009), e no Brasil, Gallardo (2013) e Heberle (2005). Embora haja exceções, a maioria das redes sociais virtuais gira em torno de relações já existentes, e não da

\footnotetext{
${ }^{11}$ A coleta dos dados iniciais foi feita por meio da análise de um questionário que enviamos por e-mail para sete amigos do meio virtual. Antes do envio do questionário, enviamos uma mensagem privada (via Facebook) com o seguinte conteúdo "Hey, Xxxx! What's up? I'm doing a university research about online interaction, more specifically, about code switching practices on Facebook posts and messages. Since you are a bi-/multilingual speaker, it would be great if you could participate! Basically, I will use some examples of your posts/public messages to illustrate my work. Please inform your e-mail address to me, so I can send more information about it, all right? Kisses". Além do questionário, enviamos um termo de consentimento livre e esclarecido, os dois anexos em um único e-mail. Os sete selecionados aceitaram o convite e nos enviaram de volta o e-mail com o questionário respondido e o termo assinado.
} 
criação de novas relações com estranhos. Como sugerido pelas pesquisas de Ellison, Steinfield e Lampe (2007 apud BOYD; ELLISON, 2007), redes sociais como o Facebook são usadas primordialmente para manter ou solidificar uma amizade já existente no meio offline. Por mais frágil que sejam os laços, geralmente há um elemento offline em comum com as pessoas que adicionam um ao outro a sua rede de amigos. ${ }^{12}$ Sobre essa característica, Menezes de Souza e Monte Mór (2006, p. 103) afirmam que "novas práticas de linguagem surgem, adaptam-se e organizam-se de forma complexa, porém socialmente determinadas em contextos novos" e, consequentemente, trazem uma forma específica e características próprias. Sites e aplicativos, como WhatsApp, Snapchat, Facebook, Twitter, entre outros, constituem "comunidades de prática", onde novas formas de comunicação são exploradas, já que a escrita tradicional que conhecemos na escola não foi feita para a interação verbal em tempo real, face a face. Essas características fazem com que essas comunidades recontextualizem "a escrita para adquirir o imediatismo, a redundância e a natureza efêmera da fala em situações de interação verbal em tempo real" (MENEZES DE SOUZA; MONTE MÓR, 2006, p. 104). Como evidência temos, por exemplo, os emoticons, a utilização da tecla caps lock para demonstrar emoção, raiva ou excitação, o excesso de vogais nas palavras para enfatizar e outras técnicas que traduzem estados de humor, entonação etc. Entre esses recursos, verificamos que os sujeitos bi/multilíngues incluem o CS na CMC, explorando assim as possibilidades de ser e de representar o pensamento a partir da manifestação identitária fora dos limites/regras estabelecidos pela língua de uma nação. Neste caso, contam com mais de um componente linguístico-discursivo para a construção de identidades.

\section{Metodologia e contexto da pesquisa}

A metodologia utilizada neste estudo é de natureza interpretativa e exploratória. Trata-se de um estudo de caso, ou seja, consideramos os dados apresentados, como representativos de casos semelhantes. A partir da fundamentação apresentada nas seções anteriores deste artigo, abordamos a seguir os dados coletados em um contexto de interação virtual: o Facebook.

\footnotetext{
${ }^{12}$ Utilizamos aqui o termo “amigos", já que o site requer a bilateral confirmação da relação online, como é o caso do Facebook. Diferentemente de casos como o Twitter, em que a rede de conectados ao usuário é denominada "followers" (em português, seguidores).
} 
Por se tratar de uma pesquisa qualitativa, levamos em consideração o fato de que o significado das práticas além da pesquisa influencia nossas considerações sobre o evento analisado. Assim, entendemos que as subjetividades (de pesquisadores e participantes) perpassam as experiências de cada um e motivam o fenômeno pesquisado de diferentes modos. Nesse sentido, o fato de terem suas práticas observadas pode ter influenciado o comportamento dos participantes. Do mesmo modo, a interpretação dessas práticas foi instigada por fatores imbricados nos contextos que circulamos (SCHUTZ, 1962). Os dados da pesquisa nos foram enviados por e-mail (questionário) e extraídos de posts públicos e interações online no Facebook. Aos participantes foi dito que se tratava de um estudo sobre o uso do CS nos meios on e off-line. ${ }^{13}$ Os participantes eram amigos que aceitaram participar do estudo. Foram convidados porque eram bi/multilíngues. Os sete convites feitos foram aceitos. O Facebook foi escolhido como contexto online porque é uma rede internacional e, por esse motivo, possibilita as interações transnacionais online. Segundo o estudo de Dwyer, Hiltz e Passerini (2007 apud BOYD; ELLISON, 2007) a confiança dos usuários para compartilhar informações é maior neste site do que em outros analisados por eles. Assim, dentro do que propomos, consideramos esta rede social propícia para a coleta do corpus desta pesquisa.

\section{Discussão dos dados: interações assíncronas}

Neste recorte, selecionamos quatro postagens e duas interações ocorridas nas páginas dos participantes e que foram publicados de modo assíncrono, ou seja, sem a presença virtual em tempo real dos amigos virtuais. As mensagens desses posts foram direcionadas a uma pessoa de modo particular, por meio do recurso de marcação; ou ainda, o usuário teve a opção de escrever diretamente no mural dos amigos.

Os participantes são falantes bi-/multilíngues dos seguintes países: Alemanha (imagem 4), África do Sul (línguas oficiais: africâner e língua inglesa, entre outras) (imagens 1 a 3) e Filipinas (línguas oficiais: filipino e língua inglesa) (imagens 5 e 6 ).

A primeira postagem na imagem 1 , a seguir, é uma mensagem de "feliz aniversário" postada no mural de um amigo, de mesma língua e nacionalidade:

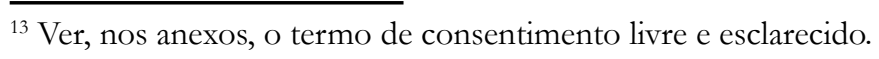




\section{IMAGEM $1^{14}$}

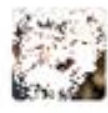

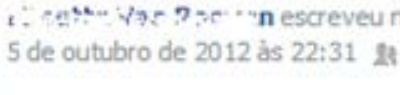

Baie geluk met jou verjaarsdag!! Hoop dit was/is awesome!

\section{Curtir - Comentar}

Classificamos o CS que ocorre nesta mensagem como intra-sentencial segmental, já que segmentos de cada língua, inglês e africâner, se alternam. A língua de base é o africâner.

Acreditamos que a interlocutora recorre ao CS para desejar coisas boas ao destinatário, como se este sentimento de satisfação não coubesse na sua LM. Nessa perspectiva, ao utilizar o CS, temos uma sensação de liberdade, primeiramente linguística, mas que possui uma densidade que vai além dos códigos linguísticos da LM pois permite expressar, acomodar um sentimento, um desejo na LE. Como se fosse para chamar a atenção à sua intensidade, a mensagem extrapola para a outra língua. $O$ verbo, grafado em dois tempos ("was"/"is"), estabelece o que foi e o que continua sendo, marcando, em outra língua, uma continuidade do que foi/ é visto-ditoapreciado.

$\mathrm{Na}$ segunda postagem (imagem 2, a seguir), a interlocutora cumprimenta o amigo pelo aniversário, em inglês, como se fosse uma saudação pública, ou seja, como se dissesse "nós dois sabemos essa língua". No entanto, usa a LM no meio da mensagem para falar sobre desejos particulares. Essa mudança de código indica ao interlocutor que "isso aqui é nosso - meu e seu". Cremos que essa atitude pode ser relacionada aos resultados das pesquisas de Ho (2006 apud CARDENAS-CLAROS; ISHARYANTHI, 2009), que apontam para a recorrência do CS para a LM quando se trata de expressar pensamentos pessoais e tópicos relacionados à intimidade entre os interlocutores, já que ao expressar os seus votos e desejos ao amigo aniversariante, o falante volta à LM.

\footnotetext{
14 “Feliz aniversário!! Espero que tenha sido/ seja incrível!".
} 
IMAGEM $2^{15}$

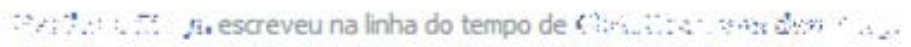

5 de outubro de 2012 às 22:53 14

Haloa! Happy happy bday! Ek hoop dit was 'n awesome dag en dat dit 'n baie geseende jaar sal wees!

Entretanto, esse tipo de interação permite interpretar que o falante continua livre para escolher a língua que quiser e, embora pareça mais à vontade para expressar intimidades na LM, ainda possui no ciberespaço um ambiente propício para a afloração da criatividade, como conclui as pesquisas de Bergs (2006 apud SHALFIE; NAYAN, 2013). Isto possibilita o experimento de variações da língua com mais frequência e criatividade do que na comunicação face a face.

Na próxima postagem (imagem 3), identificamos a ocorrência de CS também intra-sentencial unitário.

IMAGEM $3^{16}$

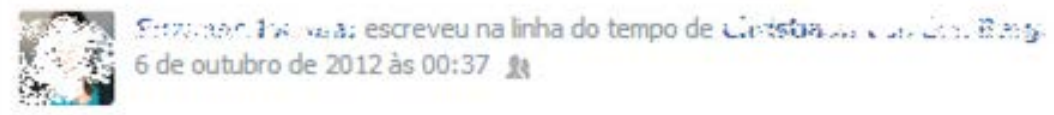

Haai neef, jammer eks so klein bietjie laat. Wou maar net baie geluk se met jou verjaarsdag en hoop jyt $n$ amazing daggie gehad. Liefde!

Entendemos que a palavra "amazing" (incrível) no meio do enunciado - incorporado ao discurso, assim como no exemplo da imagem 1 neste estudo, fala mais do que cabe na LM, para exprimir uma coisa boa.

\footnotetext{
15 "Haloa! Feliz feliz aniversário! Espero que tenha sido um dia maravilhoso e que seja um ano muito abençoado!”.

16 "Ei prima, desculpe o atraso. Apenas desejo boa sorte pelo seu aniversário e espero que você tenha um dia incrível. Com amor!"
} 
Entre multilíngues é recorrente a utilização deste formato de CS, seja para suprir uma necessidade do vocabulário ou para exprimir uma ideia específica, que torna-se mais compreensível na utilização de outra língua, uma língua cuja cultura faz uso frequente dessa estratégia. A esse respeito, recorremos à proposição de Myers-Scotton (1993), que considera que há a escolha de uma variante em detrimento de outra expressão de significado social, trazendo, assim, à discussão a negociação de identidades na interação, conforme salienta Mozzillo (2009).

A postagem a seguir (imagem 4) é de um alemão e foi colocada em seu próprio mural. O CS usado classifica-se como intersentencial, entre sentenças. A língua de base não é nem a materna, nem a segunda língua, mas sim a língua portuguesa (doravante chamada de LP).

IMAGEM $4^{17}$

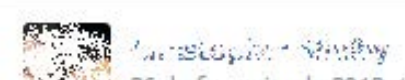 \\ a. 26 de fevereiro de 2012 a}

Concurso amanha!!! Tomorrow is the big competition for the job in Assis!!! Wish me luck!

Ver tradução

Curtir · Comentar $\cdot$ Compartihar

辽 13 प 8

O CS aqui, considerando o contexto da mensagem, ou seja, postada em mural público, sem destinatário específico, mas aberto para todos os amigos virtuais, faz-nos refletir que tem como função qualificar a mensagem, conforme elenca Grosjean (1982 apud MOZZILLO 2009) ao tratar dos motivos para o CS. Ou seja, enquanto nos comunicamos com o mundo, precisamos tornar nossa mensagem mais ampla e, ao levar em conta a diversidade linguística presente na rede de amigos do Facebook deste falante, consideramos que este era recém-chegado ao Brasil. Neste caso, a utilização da língua local promoveu, de certa forma, uma sensação de proximidade. No entanto, o falante sentiu a necessidade de se fazer entendido por sua

\footnotetext{
17 “Concurso amanhã!!! Amanhã é o grande concurso pelo trabalho em Assis! Me desejem sorte!".
} 
lista de amigos e, assim, enunciou algo sobre si mesmo não somente a seus amigos brasileiros e alemães, mas a todos os amigos estrangeiros. Deixa isso claro quando, ao final da mensagem, usa o CS supostamente para ser compreendido pelos amigos que falam inglês, língua do local em que cresceu (EUA). Note que, neste momento, ele não faz uso do CS para a LP, pois, conforme a hipótese deste artigo, este fenômeno acontece, entre outros fatores, de acordo com o objetivo da interação e dos interlocutores aos quais a mensagem é dirigida. $\mathrm{Na}$ imagem 4, este é para que os amigos do participante lhe "desejem sorte".

A postagem abaixo (imagem 5) foi feita por uma jovem das Filipinas, em seu próprio mural, mas direcionada a uma amiga, por meio do recurso "Marcação".

\section{IMAGEM $5^{18}$}

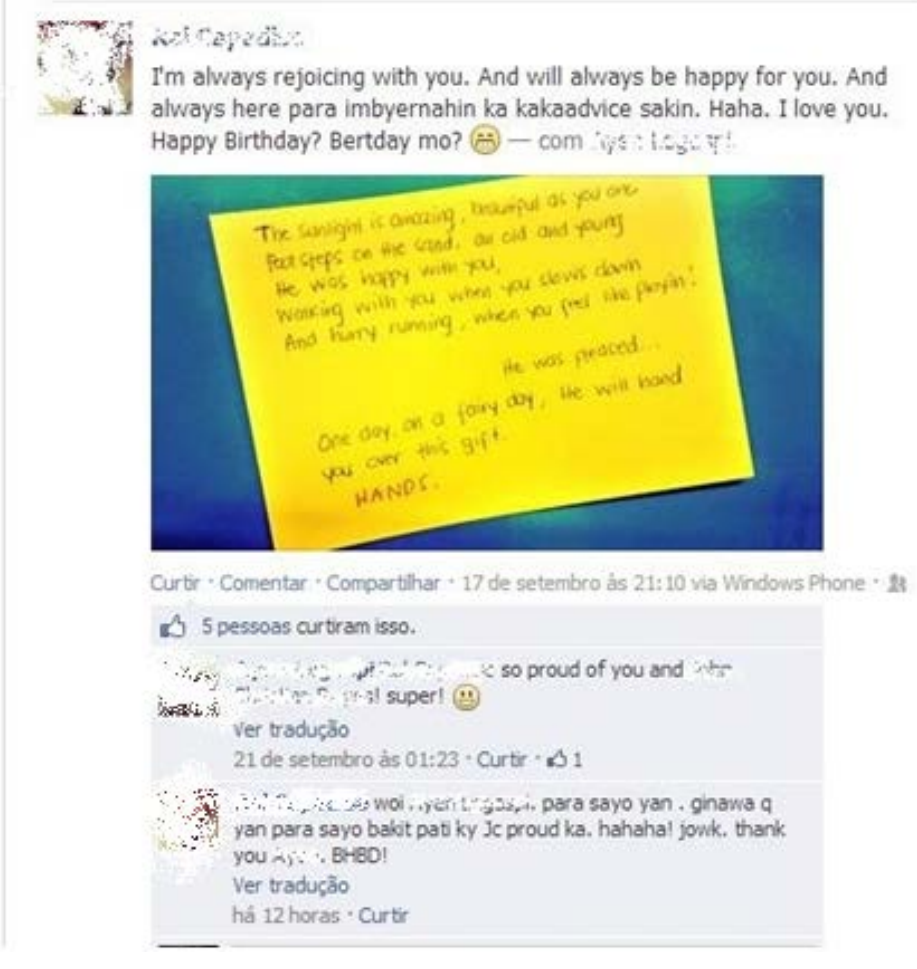

\footnotetext{
18 "Estou sempre me alegrando com você. E sempre estarei feliz por você. E sempre aqui por você. Haha Eu te amo. Feliz Aniversário? Birhday mo? (Uso do sotaque filipino).”. Resposta (comentário 1): “Muito orgulhosa de você e (cita alguém). Super!!”.
} 
$\mathrm{Na}$ mensagem, ocorre o CS intra-sentencial segmental, sem adaptação à língua de base, neste caso, a LI, que, juntamente ao filipino, é a língua oficial do país.

Notamos que, no momento da interação, a amiga compreende a mensagem e responde em inglês. Em seguida, a primeira comenta mais uma vez, agora usando o filipino como língua de base. Ela utiliza, neste momento, apenas uma expressão em inglês. $O$ sentimento foi externado na LE. Todavia, no meio dessa exposição havia algo particular, íntimo das duas interlocutoras, que foi expresso na LM. O CS foi usado, neste caso, para valorizar o sentimento de amizade pela interlocutora, resgatar a intimidade e traçar identidade, numa visão relacional.

A próxima imagem (imagem 6) corresponde a uma interação na qual cada um fala a língua que mais se ajusta ao que vê (na concepção de cada interlocutor envolvido). Ou seja, não há regras. A risada que abre a conversa é em inglês, uma das mais comuns no universo virtual transnacional de comunicação.

IMAGEM $6^{19}$

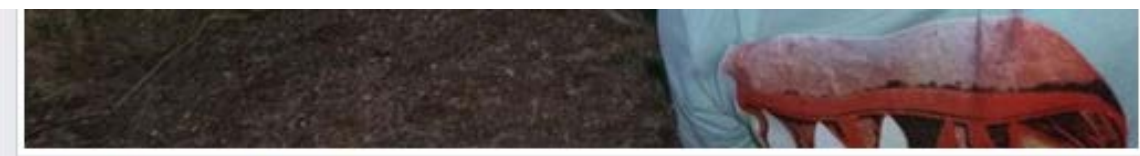

Curtir - Comentar · Compartilhar

3 pessoas curtiram isso.

The janeiro às 04:02 - Curtir

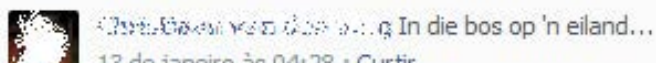

13 de janeiro às 04:28 - Curtir

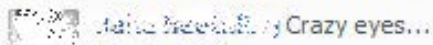

L.

13 de janeiro às 04:48 - Curtir

(1)

_....

gesien het nie... (-)

13 de janeiro às $14: 01$ : Curtir

${ }^{19}$ Comentário 1: "Hahahaha!!!”; Comentário 2: "Na floresta em uma ilha...”; Comentário 3: "Olhos loucos"; Comentário 4: "Você parece um pouco assustada!!! Não é assim que você estava a última vez que te vi... (emoji)". 
O comentário na LM após a risada é seguido de "crazy eyes" (em português, olhos loucos), indicando, assim, uma descontração, marcada pela informalidade e intimidade dos interlocutores que dominam a segunda língua. As interlocutoras se entendem em uma relação que podemos considerar como uma verdadeira manifestação de multilinguismo: fala-se em uma língua e o outro falante responde em outra, e tudo soa natural para quem participa da conversa (CANAGARAJAH, 2013). Quem vai determinar qual língua utilizar e se fará uso do CS é o próprio falante, somando as consequências e os ganhos, num campo de constantes reconfigurações identitárias.

Essa e outras postagens e interações são exemplos de que, nas interações multilíngues, a língua da postagem não determina a língua dos comentários e que os interlocutores transitam entre línguas, conforme os fatores apontados previamente (relação com o interlocutor, objetivos, fatores sociais, questões identitárias etc.).

\section{Considerações finais}

Durante muito tempo, o CS foi considerado um fator negativo na comunicação, uma forma impura de expressão usada por pessoas bilíngues que não sabiam falar nenhuma das duas (ou mais línguas) de forma plenamente correta (SHIN, 2017). Foi a partir da publicação do estudo sobre este fenômeno, publicado por Gumperz e Hymes, em 1972, que pesquisadores da área da linguagem começaram a considerar o CS como uma forma de expressão complexa, que exige uma competência sociolinguística e cultural (MOZZILLO, 2009). Este estudo teve como objetivo observar a manifestação de CS em interações online no Facebook, uma rede social que incentiva a experimentação de identidades, provocando, assim, diferentes sensações (devido à falta da presença física) e formas diversas de interação. Consequentemente, também exige novas competências dos usuários.

A conectividade mundial e o domínio de mais de uma língua permitem que os sujeitos circulem pelas dinâmicas locais de vários pontos do globo, colocando em contato o impacto de ideias globais nas práticas do cotidiano físico dos sujeitos. Kramsch e Uryu (2011, p. 223) afirmam que "operar entre línguas significa saber qual língua usar com quem, com que efeito, quando falar e quando ficar calado, quando falar sobre algo na presença de 
alguém, e assim, dominar o significado do CS". ${ }^{20}$ Esta habilidade requer de sujeitos bi/multilíngues o conhecimento de práticas discursivas, tais como a intertextualidade, a interdiscursividade e a recontextualização (BRIGGS; BAUMAN, 1992 apud KRAMSCH; URYU, 2011), apropriadas em meio às ideologias de seu contexto social.

Em alguns casos, o CS nos dados analisados indicou a busca de afetividade como resgate à intimidade entre os interlocutores, por exemplo, quando o falante intuiu que na língua usada estava, de certa forma, o distanciando de seu interlocutor. Em outros casos, o CS serviu como suporte para uma melhor expressão do que se queria dizer. Isto aconteceu quando a LM não dava conta de abarcar o significado desejado. Em vários casos, o CS apontou que, conforme as contribuições de Rajagopalan (2004), nossa identidade linguística caracteriza-se pelas diversas instabilidades perante interlocutores em geral. Ademais, o CS observado nos dados evidenciou a capacidade dos participantes alternarem códigos, de tal forma que demonstraram o conhecimento dos contextos situacionais e culturais, fato que, segundo Milroy e Muysken (1995), releva um nível alto de proficiência nas duas línguas.

A análise das interações mostrou também que bilíngues e multilíngues possuíam determinada autonomia para alternar línguas de acordo com suas necessidades, sem obedecer estritamente a regras predeterminadas (além das estruturas das línguas, como sujeito, verbo e objeto). A influência de tal autonomia partiu do assunto tratado e do grau de intimidade desejado, as motivações pessoais e contextuais diversas, confirmando a nossa hipótese.

O modelo teórico de Myers-Scotton (1993), que vê o falante como um ator criativo graças às escolhas linguísticas multilíngues foi verificado na análise. No entanto, a premissa de que isso acontece de forma intencional não ficou 100\% comprovada. Nossa análise indicou que as ocorrências de CS verificadas aconteceram tanto de forma inconsciente e imprevista, em alguns casos, como de forma consciente, em outros.

Com a análise dos dados, buscamos evidenciar a dinamicidade da língua e a flexibilidade que o conhecimento de diferentes códigos de duas

\footnotetext{
${ }^{20}$ No original: "operating between languages means knowing which language to use with whom, to what effect, when to talk, when to remain silent, when to speak about what and in the presence of whom, and the significance of code-switching" (KRAMSCH; URYU, 2011, p. 223).
} 
ou mais línguas oferece. As análises indicaram as possibilidades de extensão de modos de expressão dos usuários da internet que transitam entre línguas e culturas diversas. Com esses resultados, pretendemos ainda questionar o lugar-comum da linguagem enquanto um simples instrumento/ferramenta de comunicação, sugeridos por concepções de linguagem tradicionais e ainda utilizados no ensino e aprendizado de línguas estrangeiras, não somente nas salas de aula brasileiras, mas em todo o mundo. ${ }^{21}$

\section{Contribuição das autoras}

As duas autoras organizaram o esqueleto do artigo. A primeira autora coletou os dados e a segunda definiu a metodologia da pesquisa. As duas autoras pesquisaram e definiram as referências: a primeira, sobre CS e a segunda, sobre linguagem, identidade e internet. Fizeram a análise dos dados separadamente e, posteriormente, a revisão do trabalho uma da outra.

\section{Referências}

BATHIA, T.; RITCHIE, W. Introduction. In: (Ed.). The Handbook of Bilingualism. Oxford: Blackwell Publishing, 2004.

BRAGA, D. B. Letramento na Internet: O que mudou e como tais mudanças podem afetar a linguagem, o ensino e o acesso social. In: KLEIMAN, A.; CAVALCANTI, M. C. (Org.). Linguistica Aplicada: suas faces e interfaces. Campinas: Mercado de Letras, 2007.

BOYD, D. M.; ELLISON, N. B. Social Network Sites: Definition, History, and Scholarship. Journal of Computer-Mediated Communication, 2007. Disponível em: <http://onlinelibrary.wiley.com/doi/10.1111/j.1083-6101.2007.00393.x/full>. Acesso em: 10 set. 2013.

BUZATO, M. E. K. Letramento e inclusão: do estado-nação à era das TIC. DELTA, São Paulo, v. 25, n. 1, p. 1-38, 2009. DOI: https://doi.org/10.1590/ S0102-44502009000100001

CANAGARAJAH, S. Transligual Practice: Global Englishes and Cosmopolitan Relations. New York: Routledge, 2013.

${ }^{21}$ A esse respeito, ver, por exemplo, a análise de Leffa (2016) sobre o aplicativo Duolingo. 
CÁRDENAS-CLAROS, M. S.; ISHARYANTI, N. Code Switching and Code Mixing in Internet Chatting: Between 'Es', 'Ya', and 'Si': A Case Study. JaltCallJournal, [S.1.], v. 5, n. 3, p. 67-78, 2009. Disponível em: <http://journal.jaltcall.org/ articles/5_3_Cardenas.pdf>. Acesso em: 11 set. 2013.

CORACINI, M. J. Língua materna-estrangeira: entre saber e conhecer. In: A celebração do outro: arquivo, memória e identidade. Campinas: Mercado das Letras, 2007.

CRYSTAL, D. English as a Global Language. 2. ed. Cambridge: Cambridge University Press, 2003. Doi; https:/ / doi.org/10.1017/CBO9780511486999

CRYSTAL, D. Language and the Internet. Cambridge: Cambridge University Press, 2001. DOI: https://doi.org/10.1017/CBO9781139164771

CUCHE, D. A noção de cultura nas ciências sociais. 2. ed. Bauru: EDUSC, 2002.

GALLARDO, B. C. Comunicação transnacional no Facebook: uma análise discursiva das identidades digitais de professores de língua estrangeira em formação. 2013. Tese (Doutorado em Linguística Aplicada) - Universidade Estadual de Campinas, Campinas, 2013.

GALLARDO, B. C. Construções identitárias no Facebook de professoras de inglês em formação. In: BUZATO, M. E. K. (Org.). Cultura digital e linguística aplicada: travessias em linguagem, tecnologia e sociedade. Campinas: Pontes, 2016. v. 1.

GARCÍA, O. Bilingual Education in the 21st Century. Oxford: Wiley-Blackwell, 2009.

GEE, J. P. An Introduction to Discourse Analysis: Theory and Method. 2. ed. London: Routledge, 2005.

GUMPERZ, J. Discourse Strategies. Cambridge: Cambridge University Press, 1982. DOI: https://doi.org/10.1017/CBO9780511611834

HALL, S. A identidade cultural na pós-modernidade. 11. ed. Rio de Janeiro: DP\&A, 2006. HERRING, S. C. Introduction. In: . (Ed.). Computer-Mediated Communication: Linguistic, Social and Cross-Cultural Perspectives. Amsterdam: Benjamins. Disponível em: <http://ella.slis.indiana.edu/ herring/cmc.intro.1996.pdf>. Acesso em: 13 out. 2013.

JACOBSON, R. Codeswitching as a Worldwide Phenomenon. New York: Peter Lang, 1998. DOI: https://doi.org/10.1515/9783110812190

JUNQUEIRA, E. S.; BUZATO, M. E. K. New Literacies in Context of Brazilian Historical Social Economic Inequality: Past, Present and Future Trends. In: (Ed.). New Literacies, New Agencies? A Brazilian Perspective on Mindsets, Digital Practices and Tools for Social Action In and Out of School. New York: Peter Lang Pub., 2013. v. 64. 
KRAMSCH, C.; URYU, M. Intercultural Contact, Hybridity and Third Space. In: JACKSON, J. (Ed.). The Routledge Handbook of Language and Intercultural Communication. London; New York: Routledge, 2011.

KRESS, G.; VAN LEEUWEN, T. Reading Images: The Grammar of Visual Designs. 2. ed. New York: Routledge, 2006. DOI: https://doi.org/10.4324/9780203619728 LANKSHEAR, C.; KNOBEL, M. New Literacies: Changing Knowledge and Classroom Practice. Buckingham: Open University Press, 2009.

LÉVY, P. A inteligência coletiva: por uma antropologia do ciberespaço. Tradução de Luiz Paulo Rouanet. 8. ed. São Paulo: Loyola, 2011.

LÉVY, P. Cibercultura. 2. ed. São Paulo: Editora 34, 2007.

MARCUSCHI, L. A. Produção textual, análise de gêneros e compreensão. São Paulo: Parábola, 2008.

MENEZES DE SOUZA, L. M. T.; MONTE MÓR, W. Conhecimento de línguas estrangeiras. In: BRASIL. Orientaşões curriculares para o ensino médio: linguagens, códigos e suas tecnologias. Brasília, DF, 2006. Disponível em: <http://portal. mec.gov.br/seb/arquivos/pdf/book_volume_01_internet.pdf $>$. Acesso em: 18 jul. 2013.

MONTES-ALCALÁ, C. Written Codeswitching: Powerful Bilingual Images. In: JACOBSON, I. R. (Ed.). Code-Switching Worldwide II. Berlin: Mounton de Gruyter, 2001. DOI: https://doi.org/10.1515/9783110808742.193

MOZZILLO, I. O code-switching: fenômeno inerente ao falante bilíngue. PAPLA: Revista Brasileira de Estudos Crioulos e Similares, São Paulo, v. 19, p. 85-200, 2009. Disponível em: http://abecs.net/ojs/index.php/papia/issue/view/9. Acesso em: 18 out. 2013.

MYERS-SCOTTON, C. Social Motivations for Codeswitching: Evidence from Africa. Oxford: Clarendon Press, 1993.

PORTO, R. S. Os estudos sociolingüísticos sobre o code-switching: uma revisão bibliográfica. Revista Virtual de Estudos da Linguagem - ReVEL, [S.I.], v. 5, n. 9, ago. 2007.

POSTER, M. Cidadania, mídia e globalização. In: MORAES, D. (Org.). Por uma outra comunicação: mídia, mundialização cultural e poder. Rio de Janeiro: Record, 2003.

PRATT, M. L. Os olhos do império: retratos de viagem e transculturação. Bauru: Edusc, 1999.

RAJAGOPALAN, K. Por uma linguística crítica: linguagem, identidade e a questão ética. 2. ed. São Paulo: Parábola Editorial, 2004. 
SCHUTZ, A. Collected Papers. v. 1. Deen Haag: Nijhoff, 1962.

SHALFIE, L. A.; NAYAN, S. Languages, Code-Switching Practice and Primary Functions of Facebook. Among University Students. Study in English Language Teaching, London, v. 1, n. 1, P. 187-199, 2013. DOI: http://dx.doi.org/10.22158/selt.v1n1p187. Disponivel em: <www.scholink.org/ojs/index.php/selt/article/.../97>. Acesso em: 19 set. 2013. SHIN, S. J. Social and Conversational Aspects of Code-Switching. In:

Bilingualism in Schools and Society: Language, Identity, and Policy. 2. ed. New York: Routledge, 2017. DOI: https://doi.org/10.4324/9781315535579-6

SUNDÉN, J. Material virtualities. New York: Peter Lang Publishing, 2003.

VILAÇA, M. L. C.; ARAÚJO, E. V. Questões de Comunicação na era digital: tecnologia, cibercultura e linguagem. E-scrita: Revista do Curso de Letras da UNLABEU, Nilópolis, v. 3, n. 2, p. 58-72, mai./ago. 2012. Disponível em: <http:/ /www.uniabeu. edu.br/publica/index.php/RE/article/view/457>. Acesso em: 06 out. 2012.

Data de submissão: 12/05/2018. Data de aprovação: 10/12/2018. 